\title{
EDITORIAL
}

\section{COLABORACIÓN ENTRE LAS REVISTAS DE SALUD PÚBLICA EN ESPAÑA}

Clara Bermúdez-Tamayo (1,2), Miguel Ángel Negrín (3), Carlos Alvarez-Dardet (2,4), Maa Aranzazu López Franco (5) y Pello Latasa Zamalloa (5,6)

(1) Escuela Andaluza de Salud Pública. Granada. España.

(2) Revista Gaceta Sanitaria. Madrid. España.

(3) Universidad de Las Palmas de Gran Canaria. Las Palmas de Gran Canaria. España.

(4) Universidad de Alicante. Alicante. España.

(5) Revista Española de Salud Pública. Ministerio de Sanidad. Madrid. España.

(6) Centro de Alertas y Emergencias Sanitarias. Ministerio de Sanidad. Madrid. España.

La historia de la Salud Pública en España ha sido escrita principalmente en dos revistas que actualmente siguen siendo un referente en el desarrollo académico y profesional de la misma. Con trayectorias dispares, la Revista Española de Salud Pública (1926) y Gaceta Sanitaria (1888) comienzan ahora una política de cooperación que pretende situar a la Salud Pública en la agenda informativa del país.

Iniciamos el dialogo para tamaña empresa en una reunión realizada en la Escuela Nacional de Sanidad del Instituto de Salud Carlos III (Madrid) el 15 de noviembre de 2019, y mientras las burocracias a las que pertenecemos (por un lado, el Ministerio de Sanidad -MS- y, por otro, la Sociedad Española de Salud Pública y Administración Sanitaria -SESPAS-) desarrollan un acuerdo formal, nosotros, los equipos directivos de Revista Española de Salud Pública y de Gaceta Sanitaria, queremos compartir con nuestras audiencias las perspectivas que vislumbramos y abrir un debate sobre la utilidad de esta empresa de colaboración que ahora emprendemos.

Cuando dos equipos se dedican a lo mismo, la edición científica en Salud Pública en nuestro caso, lo usual es la competencia, no la colaboración. Sin embargo, pensamos que hay algo más trascendente que el éxito de cada una de nuestras revistas por separado $\mathrm{y}$ es la capacidad sinérgica de influir para mejorar la labor de los profesionales, los decisores y la opinión publica en temas de salud en España. Nuestro tándem, que aúna al sector público y a una organización profesional como SESPAS, tiene la capacidad, y diríamos que la obligación ética, de influir en la agenda española. Veremos si lo conseguimos, hay herramientas de análisis para explorar esto y nos comprometemos a monitorizar nuestra alianza en cuanto a sus resultados.

Ambas cabeceras tienen raíces históricas importantes. Gaceta Sanitaria fue fundada a finales del siglo XIX como revista médica del Ayuntamiento de Barcelona, y durante los años 80 su cabecera fue cedida a SESPAS por Joan Clos, iniciándose un interesante desarrollo que la llevó a ser incluida primero en MedLine y luego en el Science Citation Index. Estos hitos los consiguió antes la Revista de Sanidad e Higiene Pública (ahora RESP), única representante de España durante muchos años en los repositorios internacionales. La Revista de Sanidad e Higiene Pública fue el resultado del impulso 
del desarrollo de la salud pública en EEUU y Europa que efectuó la Fundación Rockefeller durante los años 20 y 30 del pasado siglo, el cual fue el comienzo de la actividad profesional en este campo profesional en España.

En los últimos 30 años el panorama de la edición científica en el mundo ha cambiado dramáticamente, a consecuencia de la aparición de Internet, del acceso abierto para las publicaciones científicas (necesario para la reutilización óptima de los datos obtenidos de la investigación) y a la irrupción de revistas depredadoras, que suponen un enorme fraude mundial como consecuencia de la presión por publicar que tienen los profesionales. Esto dificulta la tarea de mantenerse y mejorar en este ambiente complejísimo e, incluso, agresivo. Para ello es imprescindible innovar en nuestros procesos de publicación, pero basándonos siempre en la mejor evidencia disponible. Por ejemplo, la RESP ofrece desde 2013 publicación continua a través de su web, mientras que GS mantiene volúmenes y números con su paginación. Una de las consecuencias de la colaboración entre ambas revistas puede ser compartir experiencias en cuanto a edición científica y reproducir las experiencias que funcionan, ya que compartimos el mismo público objetivo y tipo de autores. Entre las dos revistas sumamos casi 1.000 artículos recibidos cada año y un número suficiente de envíos a revisión como para poder hacer buenos proyectos de investigación sobre edición científica

Por otro lado, en España dentro de las carreras sanitarias se exige haber publicado en revistas científicas para el acceso a puestos de trabajo y para la promoción en los mismos, sin embargo, ningún baremo apoya a la publicación de esas revistas. Ser director, miembro de los consejos editoriales o revisor para una revista científica califica en el apartado de otros méritos, al albur de la buena intención de los evaluadores. Nos proponemos, con la ayuda de otras revistas científicas españolas, iniciar una campaña para que estas cuestiones tengan su justo reflejo en las valoraciones profesionales, prestigiando estas tareas imprescindibles para nuestro sistema de I+D.

Otra tarea que nos compete en nuestra alianza es la defensa de la publicación en nuestra lengua, pues la presión del inglés es enorme. Ambas revistas somos miembros de las plataformas Scielo España y Scielo Salud Pública, y pretendemos seguir en ellas y eventualmente conseguir que se calculen factores de impacto bibliométricos ajustados por lengua de publicación es algo justo, deseable y posible.

También tenemos que pensar en el futuro y en nuestros sucesores. La edición científica es una actividad fascinante que merece ser apoyada, y ambos equipos tanto en la RESP como en GC tenemos experiencia acumulada que merece la pena ser compartida. Pronto haremos pública una oferta conjunta de cursos para la formación en edición, autoría y revisión de trabajos de investigación. Esta línea formativa pretende mejorar la calidad científica de los trabajos y facilitar la publicación a todos aquellos profesionales que se dedican, bien desde la investigación o desde la administración sanitaria, a la Salud Pública.

El objetivo final no es solo influir en la agenda sanitaria sino además potenciar la labor de ambas revistas y su posicionamiento en el ámbito de las publicaciones científicas. 